
\title{
28 Research Suare \\ Prognostic factors in patients with thyroid carcinoma: a competing-risks analysis
}

\author{
Junhu Wang \\ Honghui Hospital, Xi'an Jiaotong University, Xi'an, Shaanxi, China; \\ Lisong Heng \\ Honghui Hospital, Xi'an Jiaotong University, Xi'an, Shaanxi, China; \\ Jie Yang \\ Honghui Hospital, Xi'an Jiaotong University, Xi'an, Shaanxi, China; \\ Feng Tian \\ Honghui Hospital, Xi'an Jiaotong University, Xi'an, Shaanxi, China; \\ Xiaojun Liang \\ Honghui Hospital, Xi'an Jiaotong University, Xi'an, Shaanxi, China; \\ xinwen wang ( $\nabla$ wangxinwen139@163.com ) \\ Honghui Hospital, Xi'an Jiaotong University https://orcid.org/0000-0001-8087-7280
}

\section{Research article}

Keywords: competing-risks analysis, SEER, thyroid carcinoma

Posted Date: May 26th, 2020

DOl: https://doi.org/10.21203/rs.3.rs-19798/v2

License: (c) (i) This work is licensed under a Creative Commons Attribution 4.0 International License.

Read Full License 


\section{Abstract}

Background: Cox proportional-hazards models are widely used to describe survival trends and identify prognostic factors for thyroid carcinoma, but the prognostic model is not accurate enough. This study therefore used a competing-risks model to identify the significant prognostic factors for different types of thyroid carcinoma.

Methods: We identified 38,444 eligible patients in the SEER (Surveillance, Epidemiology, and End Result) database. The potential prognostic factors for thyroid carcinoma were analyzed by Cox regression analysis, cause-specific hazard function (CS) analysis, and subdistribution hazard function (SD).

Results: Cox regression analysis, CS analysis and SD analysis found identifying age, being unmarried, no regional lymph nodes examined, AJCC-6 II, III, IV vs I , having follicular, medullary, anaplastic vs Papillary carcinomas, no surgery, no radioiodine, liver metastasis, and lung metastasis as the significant risk factors for thyroid carcinoma, while being female was protective factor. However, the results from the three multivariate models for being black, tumor size $>1 \mathrm{~cm}$, and brain metastasis were inconsistent.

Conclusion: In addition to finding that age, pathological type, tumor size, AJCC-6 stage, surgery status, radioiodine status, metastasis as common factors affected the prognosis, we also found that women, being unmarried and had their regional lymph nodes examined can improve the prognosis of thyroid cancer. The discovery of these factors will provide evidences for the prevention and treatment of thyroid cancer.

\section{Background}

The detection rate of thyroid cancer is continuing to increase. Its incidence is increasing faster than that of any other solid tumor, and it was ranked in ninth place for incidence in 2018 and is predicted to replace colorectal cancer as the fourth leading cancer diagnosis by 2030 in the USA. Although thyroid cancer has an excellent prognosis, it still kills estimated 41,000 people annually worldwide, approximately [1]. The main pathological types of thyroid carcinoma are papillary thyroid carcinoma (PTC), follicular thyroid carcinoma (FTC), anaplastic thyroid carcinoma (ATC), and medullary thyroid carcinoma (MTC)[2], with PTC constituting $90 \%$ of them. Most cases have an excellent prognosis, but approximately $10 \%$ of PTC patients exhibit recurrences such as lung metastasis and lymph node recurrence[3], or even death. Although much less common, FTC is widely invasive, and it is reported that the mortality rate is about $20 \%[4]$. ATC is an extremely aggressive undifferentiated tumor, with almost $100 \%$ disease-specific mortality [5], and while representing about only $<2 \%$ of thyroid cancers ATC is responsible for $40 \%$ of thyroid cancer deaths. MTC represents $<5 \%$ of thyroid carcinomas, and the overall 5 -year survival rate of patients with MTC is $86 \%[6]$.

Adequate risk stratification is crucial in a malignant neoplastic disease in order to avoid both the undertreatment of high-risk subjects and the overtreatment of low-risk patients[7]. This means that personalized treatment according to the potential prognosis of individual patients with thyroid cancer is 
critically important. Cox regression is currently the most widely used method to predict the risk factors for thyroid cancer[8-11]. It is used for a single end point for clinical outcome, but in fact clinical survival data are often associated with multiple outcomes, and these outcomes compete with each other, such as death due to cancer and death due to other causes. The use of Cox regression analysis may lead to inaccurate estimates of hazard ratios (HRs) $[12,13]$. A competing-risks model is better than a Cox regression model in such situations in clinical epidemiology[14-16], and is quickly becoming a highly regarded approach for analyzing time-to-event data in the presence of competing events[17].However, competing-risks analyses of the prognostic factors in patients with thyroid carcinoma have rarely been reported.

A competing risk refers to a situation where an individual is exposed to multiple causes of failure, with the eventual failure being attributed to exactly one of them. In this situation, the occurrence of one type of event hinders the occurrence of any other event[18]. In our research, the failure events were death due to thyroid carcinoma, but the death due to DOC prevented the occurrence of failure events. There was competition between death due to thyroid carcinoma and death due to DOC. We used the competing-risks model to analyze the significant prognostic factors for thyroid carcinoma in order to guide clinical treatment more accurately.

\section{Methods}

\section{Patients}

The patient data were obtained from the latest version of the SEER (Surveillance, Epidemiology, and End Result) database using SEER`Stat software (version 8.3.5 released on April 15, 2019;

https://seer.cancer.gov/). This study was approved by the Ethics Committee of Honghui Hospital, Xi'an Jiaotong University, Xi'an. The following inclusion criteria were applied:

1. Presence of thyroid carcinoma according to ICD-0-3/WHO 2008 histological type of FTC, PTC, MTC, and ATC.

2. Histology diagnostic confirmation were FTC, PTC, MTC, and ATC.

3. Categorized as alive, death due to thyroid cancer, or DOC.

4. Active follow-up.

5. Age at diagnosis of $19-85$ years.

The exclusion criteria were as follows:

1. Unknown age, race, sex, or American Joint Committee on Cancer (AJCC 6th Edition) stages , or incomplete SEER cause-specific death classification.

2. Unknown survival time for a patient who was still alive.

3. Diagnosis based only a death certificate or an autopsy because of no follow-up data. 
We collected the following data for each patient: age, race, sex, marital status, insurance status, tumor size, whether regional lymph nodes were removed and examined by the pathologist, AJCC- 6 stage, histology, surgery status, radioiodine status, chemotherapy status, bone metastases, brain metastases, liver metastases, lung metastases, survival time (in months), and case outcome. The case outcome was divided into the following three conditions: alive, death due to thyroid carcinoma (endpoint event), and DOC (competing event).

The application of the inclusion and exclusion criteria resulted in the identification of 38,444 patients in the SEER database between January 01, 2010 and December 31, 2015.

\section{Statistical analysis}

All statistical analyses were performed using SPSS (version 21.0) and SAS 14 (performing competing risks modeling). Mean \pm standard-deviation values were used to express continuous variables conforming to a normal distribution, and all other variables were expressed as median (25th-75th percentile) values. The cumulative incidence function (CIF) was used in the univariate analysis to analyze each potential prognostic factor, and Gray's test used for the difference test. Cox regression analysis and the competitive risk model (CS analysis and SD analysis) were used for the multivariate analyses, and independent prognostic factors were obtained. Probability values of $p<0.05$ were considered statistically significant.

\section{Results}

\section{Patient characteristics}

The median age of all patients was 46 years, with an age range from 35 to 57 years. The median age of patients who died due to thyroid cancer was 68 years, with an age range from 57 to 77 years. Most of the patients in both groups (the total patient group and died due to thyroid cancer group) were female, white, and married, had insurance and any medical, a tumor size of $£ 1 \mathrm{~cm}, \mathrm{PTC}$, had their regional lymph nodes examined, had received surgery, and had not received chemotherapy. Most of the patients who died due to thyroid cancer were in AJCC- 6 stage IV, had not received radioiodine, and had an unknown metastasis status. However, most of the patients in the total patient group were in AJCC-6 stage I, had received radioiodine, and did not have metastasis. The demographics and tumor characteristics of the patients are summarized in Table 1.

\section{Univariate analysis}

Gray's test was used to perform a univariate analysis of the following 16 potential prognostic factors: age, sex, race, marital state, insurance status, tumor size, whether regional lymph nodes were examined, AJCC- 6 stage, histology, surgery status, radioiodine status, chemotherapy status, bone metastasis, brain metastasis, liver metastasis, and lung metastasis. All 16 factors were found to significantly affect the prognosis for death caused by thyroid carcinoma $(p<0.05)$. In addition, the cumulative incidence rates at 50 and 100 months were calculated, as presented in Figure 1 and Table 2. 


\section{Multivariate analyses}

The application of Cox regression analysis, CS analysis, and SD analysis for the multivariate analyses produced different results. Age, being unmarried, no regional lymph nodes examined, AJCC-6 stages II, III, and IV, having FTC, MTC, and ATC, no surgery, no radioiodine, liver metastasis, and lung metastasis were found to be significant risk factors for thyroid carcinoma in all three methods, while being female and not receiving chemotherapy were protective factors. The HR values for these predictive factors differed between the three models.

Cox regression analysis showed that being black $(p=0.01, H R=1.25)$ was a risk factor, while the SD analysis $(p=0.6)$ and CS analysis $(p=0.25)$ did not. Cox regression analysis showed that tumor size $>1 \mathrm{~cm}$ $(p=0.13)$ was not statistically significant, while the $S D$ analysis $(p<0.01, H R=2.48)$ and $C S$ analysis $(p=0.01, H R=2.59)$ showed that this was a significant risk factor. Cox regression analysis $(p<0.01$, $H R=1.93)$ and $C S$ analysis $(p=0.01, H R=1.77)$ indicated that brain metastasis was a risk factor, while the SD analysis $(p=0.09)$ did not (Table 3$)$.

\section{Discussion}

The sample size should be considered carefully when designing a competing-risks analysis. If the proportion of competing events is greater than $10 \%$, a Cox regression analysis can be severely affected by bias[19] that overestimates the event incidence and poorly estimates the HRs. The present study included 1205 DOC patients, representing almost half of the deaths, and so we used a competing-risks model that could avoid this bias to obtain more accurate prognostic factors for thyroid carcinoma. Competing-risks regression approaches focus on two definitions of hazard: SD and CS. The SD model is useful for predicting an individual's risk or when allocating resources, while the CS model may be better suited for studying the etiology of diseases[20]. Since these two models have their own unique underlying mechanisms, it is necessary to provide the results obtained from SD and CS models simultaneously. Koller et al.[21] proposed that a SD model tends to estimate the disease risk and prognosis, which is more suitable for establishing a clinical prediction model and risk scores. It is obvious that the HRs obtained in the present SD model were the most valuable, since this model focuses on the direct assessment of actual risks and therefore also the prognosis and medical decision-making.

The Cox regression analysis showed that there was no significant difference between tumor sizes of $>1$ and $£ 1 \mathrm{~cm}$, and that being black was a risk factor in the thyroid carcinoma patients. However, the competing-risks model produced the opposite results. There is a considerable amount of evidence that tumor size is an important prognostic factor for thyroid carcinoma[22]. Meanwhile, the effect of race in predicting thyroid cancer death was inconclusive in our competing-risks model. It could be that the Cox analysis overestimated the HR value for race, resulting in a false-positive result.

All three methods applied in this study indicated that older age, FTC, MTC, and ATC (all vs PTC), AJCC-6 stages II, III, and IV (all vs stage I), liver metastasis, and lung metastasis were detrimental prognostic 
factors. It is well known that age $>45$ years, extrathyroidal invasion, distant metastasis, large tumor, vascular invasion, and poor differentiated histology are detrimental prognostic factors $[4,23,24]$.

We found that the female-specific mortality was lower than the male-specific mortality in all three methods, even though the incidence rate is higher in females than males[25]. There are conflicting reports on the effect of sex on mortality. Ito and Miyauchi[26] and Lin et al.[27] found that a larger proportion of male than female patients died of thyroid cancer, whereas Nguyen et al.[28] found the opposite result. Bray et al.[25] reported that the mortality rates were similar in the sexes, based on global cancer statistics published in 2018. It is possible that any effect of sex on mortality is related to geography and race. More evidence is needed on the effect of sex on thyroid-cancer-specific death.

All three methods utilized in our study indicated that having the regional lymph nodes removed and examined by the pathologist was a significant protective factor for thyroid-cancer-specific death. There is no report in the literature on whether having regional lymph nodes examined affects the prognosis of thyroid cancer, while there is substantial evidence that local lymph node metastasis is a significant risk factor for thyroid-cancer-related death[29-33]. This suggests that in the case of unknown lymph node metastasis, the prognosis of regional lymph nodes removed and examined may be better than that of no regional lymph nodes removed and examined. As described in Shi et al.[34] and Merrill and Johnson[35], we also found that being married has a positive effect on the prognosis of thyroid cancer in all three analysis methods.

The treatment of choice for patients diagnosed with thyroid cancer is surgery, when possible. Usually, surgery is followed by treatment with radioiodine. Chemotherapy is only considered if the patient has any of the following conditions: (1) clinically significant disease and evidence of disease progression, (2) a symptomatic tumor burden that cannot be managed with localized treatments or other medical treatment, or (3) the tumor threatens vital structures and cannot be managed with localized treatments[36]. Still, the effects of chemotherapy have not been proven[37-40]. We found that receiving surgery and radioiodine therapy were protective factors, and patients in receiving chemotherapy group had a higher mortality rate than those in not receiving chemotherapy group.

While the above-mentioned factors have been demonstrated to be independent factors for the prognosis of thyroid cancer in three analysis methods, compared to the SD model, Cox regression overrated the prognostic effect of almost all of the variables we investigated, including age, sex, marital state, surgery status, radioiodine status, and metastasis, as also described by Pintilie[37-40].

\section{Conclusion}

In addition to finding that age, pathological type, tumor size, AJCC-6 stage, surgery status, radioiodine status, metastasis as common factors affected the prognosis, we also found that women, being unmarried and had their regional lymph nodes examined can improve the prognosis of thyroid cancer. The discovery of these factors will provide evidences for the prevention and treatment of thyroid cancer. 


\section{Declarations}

\section{Ethics approval and consent to participate}

This study was approved by the Ethics Committee of Honghui Hospital, Xi'an Jiaotong University, Xi'an

\section{Consent for publication}

All patients came from the SEER database (Surveillance, Epidemiology, and End Result), which is publicly available.

\section{Availability of data and material}

The datasets analyzed during current study are available from the corresponding author upon reasonable request.

\section{Competing interests}

The authors declare that they have no competing interests.

Funding: None

\section{Authors' contributions}

(1) Conception and design: Junhu Wang and Lisong Heng. (2) Administrative support: Xinwen Wang, Junhu Wang. (3) Provision of study materials or patients: Jie Yang and Xinwen Wang.(4) Collection and assembly of data: Lisong Heng, Xinwen Wang and Feng Tian. (5) Data analysis and interpretation: Xiaojun Liang, Xinwen Wang, Lisong Heng and Junhu Wang. (6) Manuscript writing: Junhu Wang and Lisong Heng. (7) Final approval of manuscript: Junhu Wang, Lisong Heng, Jie Yang, Feng Tian, Xiaojun Liang and Xinwen Wang.

\section{Acknowledgment}

We thank all colleagues involved in the study for their contributions.

\section{Abbreviations}

AJCC : American Joint Committee on Cancer

SEER : Surveillance, Epidemiology, and End Result

CD: cause-specific hazard function

SD : subdistribution hazard function

PTC: papillary thyroid carcinoma 
FTC: follicular thyroid carcinoma

ATC: anaplastic thyroid carcinoma

MTC: medullary thyroid carcinoma

HRs: hazard ratios

DOC: death due to other causes

CIF :The cumulative incidence function

\section{References}

1. Rahib L, Smith BD, Aizenberg R, Rosenzweig AB, Fleshman JM, Matrisian LM: Projecting Cancer Incidence and Deaths to 2030: The Unexpected Burden of Thyroid, Liver, and Pancreas Cancers in the United States. CANCER RES 2014, 74(11):2913-2921.

2. Jemal A, Bray F, Center MM, Ferlay J, Ward E, Forman D: Global cancer statistics. CA Cancer J Clin 2011, 61(2):69-90.

3. Mansour J, Sagiv D, Alon E, Talmi Y: Prognostic value of lymph node ratio in metastatic papillary thyroid carcinoma. J LARYNGOL OTOL 2018, 132(1):8-13.

4. Vuong HG, Kondo T, Pham TQ, Oishi N, Mochizuki K, Nakazawa T, Hassell L, Katoh R: Prognostic significance of diffuse sclerosing variant papillary thyroid carcinoma: a systematic review and metaanalysis. EUR J ENDOCRINOL 2017, 176(4):431-439.

5. Are C, Shaha AR: Anaplastic thyroid carcinoma: biology, pathogenesis, prognostic factors, and treatment approaches. ANN SURG ONCOL 2006, 13(4):453-464.

6. Giuffrida $\mathrm{D}$, Gharib H: Current diagnosis and management of medullary thyroid carcinoma. ANN ONCOL 1998, 9(7):695-701.

7. Krajewska J, Chmielik E, Jarząb B: Dynamic risk stratification in the follow-up of thyroid cancer: what is still to be discovered in 2017? ENDOCR-RELAT CANCER 2017, 24(11):R387-R402.

8. Guan YJ, Fang SY, Chen LL, Li ZD: Development and validation of prognostic nomograms for medullary thyroid cancer. Onco Targets Ther 2019, 12:2299-2309.

9. Zhang N, Cong X, Zhou D, Guo L, Yuan C, Xu D, Su C: Predictive significance of serum dipeptidyl peptidase-IV in papillary thyroid carcinoma. CANCER BIOMARK 2019, 24(1):7-17.

10. Nam SH, Bae MR, Roh JL, Gong G, Cho KJ, Choi SH, Nam SY, Kim SY: A comparison of the 7th and 8th editions of the AJCC staging system in terms of predicting recurrence and survival in patients with papillary thyroid carcinoma. ORAL ONCOL 2018, 87:158-164.

11. Teng H, Mao F, Liang J, Xue M, Wei W, Li X, Zhang K, Feng D, Liu B, Sun Z: Transcriptomic signature associated with carcinogenesis and aggressiveness of papillary thyroid carcinoma. THERANOSTICS 2018, 8(16):4345-4358. 
12. Putter H, Fiocco M, Geskus RB: Tutorial in biostatistics: competing risks and multi-state models. STAT MED 2007, 26(11):2389-2430.

13. Berry SD, Ngo L, Samelson EJ, Kiel DP: Competing risk of death: an important consideration in studies of older adults. J AM GERIATR SOC 2010, 58(4):783-787.

14. Andersen PK, Pohar PM: Inference for outcome probabilities in multi-state models. LIFETIME DATA ANAL 2008, 14(4):405-431.

15. Austin PC, Lee DS, Fine JP: Introduction to the Analysis of Survival Data in the Presence of Competing Risks. CIRCULATION2016, 133(6):601-609.

16. Lau B, Cole SR, Gange SJ: Competing risk regression models for epidemiologic data. $A M J$ EPIDEMIOL 2009, 170(2):244-256.

17. van Walraven C, McAlister FA: Competing risk bias was common in Kaplan-Meier risk estimates published in prominent medical journals. J CLIN EPIDEMIOL 2016, 69:170-173.

18. Austin PC, Lee DS, Fine JP: Introduction to the Analysis of Survival Data in the Presence of Competing Risks. CIRCULATION2016, 133(6):601-609.

19. Pintilie M: Dealing with competing risks: testing covariates and calculating sample size. STAT MED 2002, 21(22):3317-3324.

20. Lau B, Cole SR, Gange SJ: Competing risk regression models for epidemiologic data. $A M \mathrm{~J}$ EPIDEMIOL 2009, 170(2):244-256.

21. Koller MT, Raatz H, Steyerberg EW, Wolbers M: Competing risks and the clinical community: irrelevance or ignorance? STAT MED 2012, 31(11-12):1089-1097.

22. Perrier ND, Brierley JD, Tuttle RM: Differentiated and anaplastic thyroid carcinoma: Major changes in the American Joint Committee on Cancer eighth edition cancer staging manual. CA Cancer J Clin 2018, 68(1):55-63.

23. Ito Y, Hirokawa M, Higashiyama T, Takamura Y, Miya A, Kobayashi K, Matsuzuka F, Kuma K, Miyauchi A: Prognosis and prognostic factors of follicular carcinoma in Japan: importance of postoperative pathological examination. WORLD J SURG 2007, 31(7):1417-1424.

24. Elisei R, Cosci B, Romei C, Bottici V, Renzini G, Molinaro E, Agate L, Vivaldi A, Faviana P, Basolo F et al: Prognostic significance of somatic RET oncogene mutations in sporadic medullary thyroid cancer: a 10-year follow-up study. J Clin Endocrinol Metab 2008, 93(3):682-687.

25. Bray F, Ferlay J, Soerjomataram I, Siegel RL, Torre LA, Jemal A: Global cancer statistics 2018: GLOBOCAN estimates of incidence and mortality worldwide for 36 cancers in 185 countries. $C A$ Cancer J Clin 2018, 68(6):394-424.

26. Ito $Y$, Miyauchi A: Prognostic factors and therapeutic strategies for differentiated carcinomas of the thyroid. ENDOCR J 2009, 56(2):177-192.

27. Lin JD, Hsueh C, Chao TC: Long-Term Follow-Up of the Therapeutic Outcomes for Papillary Thyroid Carcinoma With Distant Metastasis. Medicine (Baltimore) 2015, 94(26):e1063. 
28. Nguyen MT, Hu J, Hastings KG, Daza EJ, Cullen MR, Orloff LA, Palaniappan LP: Thyroid cancer mortality is higher in Filipinos in the United States: An analysis using national mortality records from 2003 through 2012. CANCER-AM CANCER SOC 2017, 123(24):4860-4867.

29. Yamashita H, Noguchi S, Murakami N, Kawamoto H, Watanabe S: Extracapsular invasion of lymph node metastasis is an indicator of distant metastasis and poor prognosis in patients with thyroid papillary carcinoma. CANCER-AM CANCER SOC 1997, 80(12):2268-2272.

30. Yamashita H, Noguchi S, Murakami N, Toda M, Uchino S, Watanabe S, Kawamoto H: Extracapsular invasion of lymph node metastasis. A good indicator of disease recurrence and poor prognosis in patients with thyroid microcarcinoma. CANCER-AM CANCER SOC 1999, 86(5):842-849.

31. Ito $Y$, Fukushima M, Tomoda $C$, Inoue $H$, Kihara M, Higashiyama T, Uruno T, Takamura Y, Miya A, Kobayashi $\mathrm{K}$ et al: Prognosis of patients with papillary thyroid carcinoma having clinically apparent metastasis to the lateral compartment. ENDOCR J 2009, 56(6):759-766.

32. Ricarte-Filho J, Ganly I, Rivera M, Katabi N, Fu W, Shaha A, Tuttle RM, Fagin JA, Ghossein R: Papillary thyroid carcinomas with cervical lymph node metastases can be stratified into clinically relevant prognostic categories using oncogenic BRAF, the number of nodal metastases, and extra-nodal extension. THYROID 2012, 22(6):575-584.

33. Wu MH, Shen WT, Gosnell J, Duh QY: Prognostic significance of extranodal extension of regional lymph node metastasis in papillary thyroid cancer. Head Neck 2015, 37(9):1336-1343.

34. Shi RL, Qu N, Lu ZW, Liao T, Gao Y, Ji QH: The impact of marital status at diagnosis on cancer survival in patients with differentiated thyroid cancer. Cancer Med 2016, 5(8):2145-2154.

35. Merrill RM, Johnson E: Benefits of marriage on relative and conditional relative cancer survival differ between males and females in the USA. J CANCER SURVIV2017, 11(5):578-589.

36. Cabanillas ME, McFadden DG, Durante C: Thyroid cancer. LANCET 2016, 388(10061):2783-2795.

37. Brose MS, Nutting CM, Jarzab B, Elisei R, Siena S, Bastholt L, de la Fouchardiere C, Pacini F, Paschke $\mathrm{R}$, Shong $\mathrm{YK}$ et al: Sorafenib in radioactive iodine-refractory, locally advanced or metastatic differentiated thyroid cancer: a randomised, double-blind, phase 3 trial. LANCET 2014, 384(9940):319-328.

38. Schlumberger M, Tahara M, Wirth LJ, Robinson B, Brose MS, Elisei R, Habra MA, Newbold K, Shah $\mathrm{MH}, \mathrm{Hoff} \mathrm{AO}$ et al: Lenvatinib versus placebo in radioiodine-refractory thyroid cancer. $N$ Engl J Med 2015, 372(7):621-630.

39. Wells SJ, Robinson BG, Gagel RF, Dralle H, Fagin JA, Santoro M, Baudin E, Elisei R, Jarzab B, Vasselli $\mathrm{JR}$ et al: Vandetanib in patients with locally advanced or metastatic medullary thyroid cancer: a randomized, double-blind phase III trial. J CLIN ONCOL 2012, 30(2):134-141.

40. Elisei R, Schlumberger MJ, Muller SP, Schoffski P, Brose MS, Shah MH, Licitra L, Jarzab B, Medvedev V, KreissI MC et al: Cabozantinib in progressive medullary thyroid cancer. J CLIN ONCOL 2013, 31(29):3639-3646.

\section{Tables}


Table 1 Clinical and pathological characteristics of patients with thyroid cancer.

\begin{tabular}{llll}
\hline Prognostic factors & Classification & All & $\begin{array}{l}\text { Death due to thyroid } \\
\text { cancer }\end{array}$
\end{tabular}

Number of Patients $\mathrm{n}$

Median age at diagnosis, year (interquartile range)

Sex n (\%)

\begin{tabular}{|c|c|c|c|}
\hline & Male & 9095(23.6) & 537ロ44.38ロ \\
\hline & Female & $29349(76.3)$ & 673ロ55.62ロ \\
\hline \multicolumn{4}{|l|}{ Race n (\%) } \\
\hline & White & 30589(79.57) & $916 \square 75.70 \square$ \\
\hline & Black & 1912(4.97) & $78 \square 6.45 \square$ \\
\hline & Other & $5943(15.46)$ & $216 \square 17.85 \square$ \\
\hline \multicolumn{4}{|l|}{ Married State n (\%) } \\
\hline & Married & $23508 \square 61.14 \square$ & $662 \square 54.71 \square$ \\
\hline & Unmarried & $13209 \llbracket 34.36 \square$ & $507 \square 41.90 \square$ \\
\hline & Unknown & $1727 \square 4.49 \square$ & $41 \square 3.38 \square$ \\
\hline \multicolumn{4}{|l|}{ Insurance Recode n (\%) } \\
\hline & Uninsured & 719ロ1.87ロ & $25 \square 2.07 \square$ \\
\hline & $\begin{array}{l}\text { Insured and Any } \\
\text { Medicaid }\end{array}$ & $30135 \square 78.38 \square$ & $832 \square 68.76 \square$ \\
\hline & Unknown & 7590ロ19.74』 & 353029.17ロ \\
\hline \multicolumn{4}{|l|}{ Tumor Size n (\%) } \\
\hline & $\leq 1 \mathrm{~cm}$ & $37567 \square 97.72 \square$ & $969 \square 80.08 \square$ \\
\hline & $>1 \mathrm{~cm}$ & $109 \square 0.28 \square$ & 7๑0.58ロ \\
\hline & Unknown & $768 \square 2.00 \square$ & $234 \square 19.34 \square$ \\
\hline \multicolumn{4}{|l|}{$\begin{array}{l}\text { Regional nodes Examined } \\
\text { n (\%) }\end{array}$} \\
\hline & Yes & 22695059.03ם & $611050.50 \square$ \\
\hline & None & $15672 \llbracket 40.77 \square$ & $585 \square 48.35 \square$ \\
\hline & Unknown & $77 \square 0.20 \square$ & $14 \square 1.16 \square$ \\
\hline \multicolumn{4}{|l|}{ AJCC-6 stage n (\%) } \\
\hline & I & $27321071.07 \square$ & $61 \square 5.04 \square$ \\
\hline & II & $2380 \square 6.19 \square$ & $40 \square 3.31 \square$ \\
\hline & III & 4895ロ12.73ロ & 99ロ8.18ロ \\
\hline & IV & 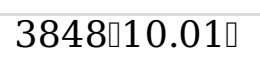 & $1010 \square 83.47 \square$ \\
\hline \multicolumn{4}{|l|}{ histology n (\%) } \\
\hline & Papillary & $34624 \square 90.06 \square$ & 592₫48.93ם \\
\hline & Follicular & $241106.27 \square$ & $141 \square 11.65 \square$ \\
\hline & Medullary & $981 \square 2.55 \square$ & 103₫8.51ロ \\
\hline & anaplastic & $428 \square 1.11 \square$ & 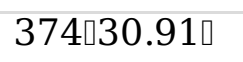 \\
\hline
\end{tabular}




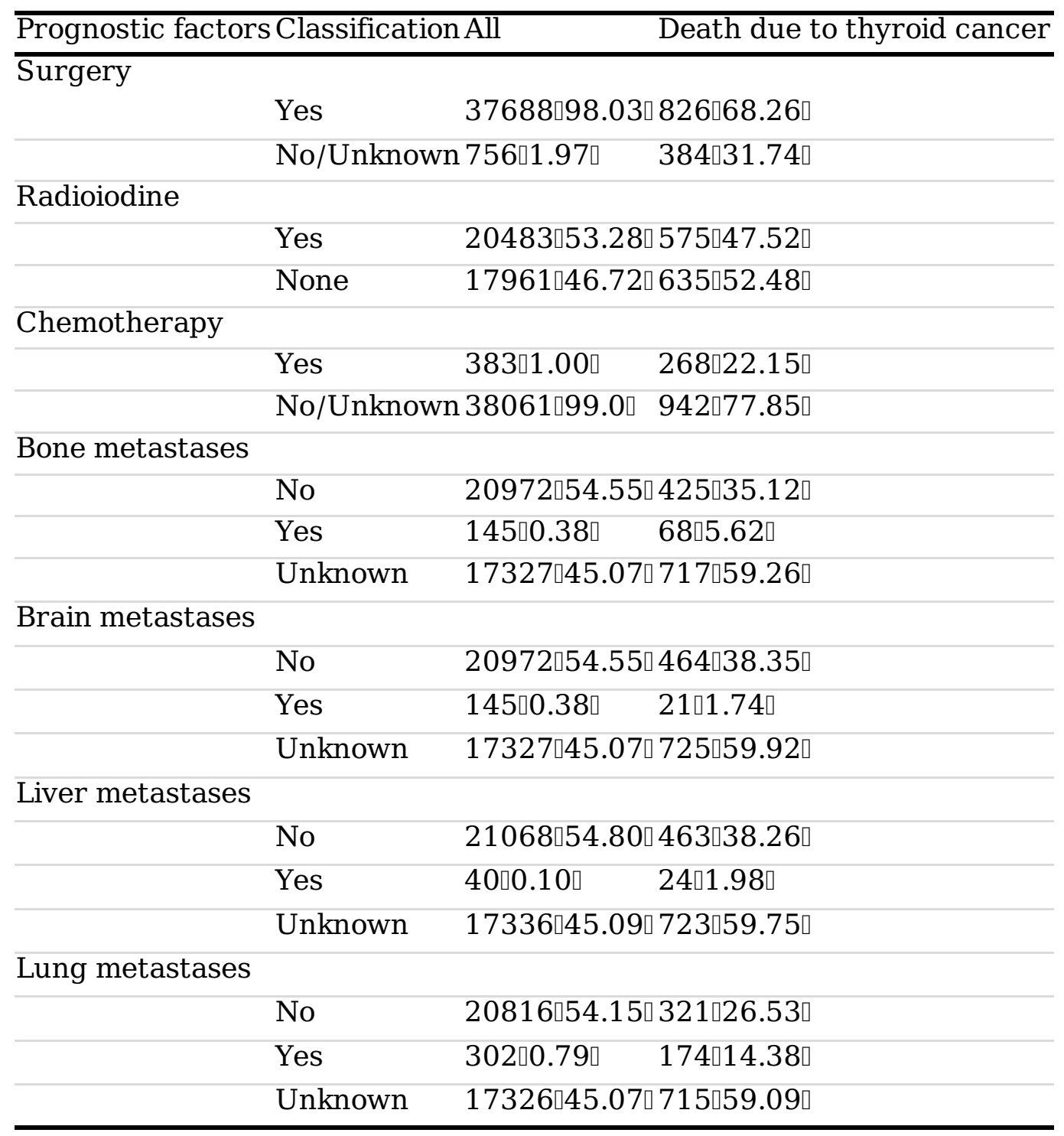

Regional nodes Examined: whether regional lymph nodes had been removed and examined by the pathologist.

Table 2 Univariate analysis of prognostic factors in patients with thyroid cancer. 


\begin{tabular}{|c|c|c|c|c|c|}
\hline \multirow{4}{*}{$\begin{array}{l}\text { Age } \\
\text { Sex }\end{array}$} & & 4078.66 & $<0.0001$ & & \\
\hline & & 294.206 & $<0.0001$ & & \\
\hline & Male & & & 0.049501 & 0.071436 \\
\hline & Female & & & 0.019922 & 0.026577 \\
\hline \multirow[t]{4}{*}{ Race } & & 14.8218 & 0.0006 & & \\
\hline & White & & & 0.025628 & 0.034991 \\
\hline & Black & & & 0.036149 & 0.048238 \\
\hline & Other & & & 0.030713 & 0.045734 \\
\hline \multirow[t]{4}{*}{ Married State } & & 34.5785 & $<.0001$ & & \\
\hline & Married & & & 0.023477 & 0.032510 \\
\hline & Unmarried & & & 0.034271 & 0.045952 \\
\hline & Unknown & & & 0.017915 & 0.034532 \\
\hline \multirow[t]{4}{*}{ Insurance Recode } & & 8.87786 & 0.0118 & & \\
\hline & Uninsured & & & 0.034382 & \\
\hline & Insured and Any Medicaid & & & 0.025231 & 0.035461 \\
\hline & Unknown & & & 0.032116 & 0.041782 \\
\hline \multirow[t]{4}{*}{ Tumor Size } & & 1864.36 & $<.0001$ & & \\
\hline & $\leq 1 \mathrm{~cm}$ & & & 0.02148 & 0.03088 \\
\hline & $>1 \mathrm{~cm}$ & & & 0.06301 & \\
\hline & Unknown & & & 0.29196 & 0.33284 \\
\hline \multirow{4}{*}{ Regional nodes Examined } & & 85.9680 & $<.0001$ & & \\
\hline & Yes & & & 0.02241 & 0.03430 \\
\hline & None & & & 0.03295 & 0.04086 \\
\hline & Unknown & & & 0.16628 & \\
\hline \multirow[t]{5}{*}{ AJCC-6 stage } & & 7623.33 & $<.0001$ & & \\
\hline & $\mathrm{I}$ & & & 0.00139 & 0.00319 \\
\hline & II & & & 0.01093 & 0.02153 \\
\hline & III & & & 0.01197 & 0.02727 \\
\hline & IV & & & 0.23749 & 0.30195 \\
\hline \multirow[t]{5}{*}{ histology } & & 11641.30 & $<0.0001$ & & \\
\hline & Papillary & & & 0.01330 & 0.02145 \\
\hline & Follicular & & & 0.04396 & 0.06957 \\
\hline & Medullary & & & 0.09138 & 0.12627 \\
\hline & anaplastic & & & 0.88337 & \\
\hline
\end{tabular}




\begin{tabular}{|c|c|c|c|c|c|}
\hline \multicolumn{4}{|c|}{$\begin{array}{l}\text { Prognostic factors Classification Gray's test P-value } \\
\end{array}$} & \multicolumn{2}{|c|}{ 50-month CIF 100-month CIF } \\
\hline \multirow[t]{2}{*}{ Surgery } & \multirow{2}{*}{\multicolumn{2}{|c|}{6649.63}} & \multicolumn{2}{|c|}{$<0.0001$} & \multirow[b]{2}{*}{0.02705} \\
\hline & & & & 0.01732 & \\
\hline & No/Unknown & & & 0.52500 & 0.56066 \\
\hline \multirow{3}{*}{ Radioiodine } & & 26.5685 & $<0.0001$ & & \\
\hline & Yes & & & 0.021760 & 0.033673 \\
\hline & None & & & 0.032753 & 0.040686 \\
\hline \multirow[t]{3}{*}{ Chemotherapy } & & 5824.72 & $<.0001$ & & \\
\hline & No/Unknown & & & 0.69220 & 0.74011 \\
\hline & Yes & & & 0.02022 & 0.02992 \\
\hline \multirow[t]{4}{*}{ Bone metastases } & & 1214.47 & $<.0001$ & & \\
\hline & No & & & 0.02094 & \\
\hline & Yes & & & 0.48200 & \\
\hline & Unknown & & & 0.02983 & 0.03965 \\
\hline \multirow[t]{4}{*}{ Brain metastases } & & 795.594 & $<.0001$ & & \\
\hline & No & & & 0.02274 & 0.6359 \\
\hline & Yes & & & & \\
\hline & Unknown & & & 0.03028 & 0.04009 \\
\hline \multirow[t]{4}{*}{ Liver metastases } & & 589.715 & $<.0001$ & & \\
\hline & No & & & 0.02276 & \\
\hline & Yes & & & 0.68281 & \\
\hline & Unknown & & & 0.03017 & 0.03998 \\
\hline \multirow[t]{4}{*}{ Lung metastases } & & 3789.35 & $<.0001$ & & \\
\hline & No & & & 0.01591 & \\
\hline & Yes & & & 0.59307 & \\
\hline & Unknown & & & 0.02972 & 0.03954 \\
\hline
\end{tabular}

Race-Other】American Indian \& AK Native \& Asian \& Pacific Islander Marital status-Unmarried $\square$ Single \& Separated \& Divorced \&Widowed \&Unmarried or Domestic Partner

Table 3 Multivariate analysis of prognostic factors in patients with thyroid cancer 


\begin{tabular}{|c|c|c|c|c|c|c|c|c|}
\hline \multirow[t]{3}{*}{ sification } & \multicolumn{5}{|c|}{ Cox regression analysis SD model analysis } & \multicolumn{3}{|c|}{ CS model analysis } \\
\hline & \multicolumn{2}{|c|}{$\begin{array}{l}\text { P-value HR } 95 \% C I \\
\end{array}$} & \multicolumn{2}{|c|}{ P-value HR } & \multirow{2}{*}{$\frac{95 \% \mathrm{CI}}{1.03-1.04}$} & \multicolumn{2}{|c|}{ P-value HR } & \multirow{2}{*}{$\begin{array}{l}95 \% \text { CI } \\
1.04-1.05\end{array}$} \\
\hline & $<0.01$ & $1.061 .06-1.07$ & $<0.01$ & 1.04 & & $<0.01$ & 1.05 & \\
\hline ale & - & - & - & - & - & - & - & - \\
\hline כmale & $<0.01$ & $0.630 .58-0.69$ & 0.02 & 0.84 & $0.72-0.97$ & $<0.01$ & 0.78 & 0.69-0.87 \\
\hline \multicolumn{9}{|l|}{$\mathrm{e}$} \\
\hline hite & - & - & - & - & - & - & - & - \\
\hline ack & 0.01 & 1.25 1.06-1.47 & 0.60 & 1.079 & $0.82-1.43$ & 0.25 & 1.16 & 0.91-1.47 \\
\hline ther & 0.09 & $0.910 .81-1.02$ & 0.35 & 1.08 & $0.92-1.26$ & 0.79 & 1.02 & $0.88-1.19$ \\
\hline \multicolumn{9}{|l|}{ ried State } \\
\hline arried & - & - & - & - & - & - & - & - \\
\hline nmarried & $<0.01$ & $1.641 .50-1.79$ & $<0.01$ & 1.328 & $31.14-1.55$ & $<0.01$ & 1.43 & $1.26-1.62$ \\
\hline nknown & 0.28 & $1.120 .91-1.38$ & 0.58 & 0.91 & $0.65-1.28$ & 0.56 & 0.91 & $0.66-1.25$ \\
\hline \multicolumn{9}{|l|}{ irance Recode } \\
\hline ninsured & - & - & - & - & - & - & - & - \\
\hline sured and Any Medicaid & 0.50 & $0.890 .62-1.26$ & 0.07 & 0.67 & $0.43-1.04$ & 0.13 & 0.73 & $0.48-1.10$ \\
\hline nknown & 0.80 & $1.050 .73-1.50$ & 0.59 & 0.88 & $0.56-1.40$ & 0.61 & 0.90 & $0.58-1.38$ \\
\hline \multicolumn{9}{|l|}{ or Size } \\
\hline $1 \mathrm{~cm}$ & - & - & - & - & - & - & - & - \\
\hline $1 \mathrm{~cm}$ & 0.13 & $1.590 .88-2.88$ & $<0.01$ & 2.48 & $1.37-4.49$ & 0.01 & 2.59 & $1.23-5.47$ \\
\hline nknown & $<0.01$ & $1.501 .30-1.74$ & $<0.01$ & 1.52 & $1.20-1.92$ & $<0.01$ & 1.71 & $1.45-2.02$ \\
\hline \multicolumn{9}{|l|}{$\begin{array}{l}\text { ional nodes } \\
\text { mined }\end{array}$} \\
\hline is & - & $-\quad-$ & - & - & - & - & - & - \\
\hline one & $<0.01$ & $1.251 .14-1.37$ & 0.01 & 1.25 & $1.06-1.47$ & $<0.01$ & 1.31 & $1.15-1.51$ \\
\hline nknown & 0.37 & $1.260 .76-2.09$ & 0.01 & 1.81 & $1.14-2.87$ & 0.06 & 1.70 & $0.98-2.93$ \\
\hline \multicolumn{9}{|l|}{ C-6 stage } \\
\hline & - & $-\quad-$ & - & - & - & - & - & - \\
\hline & $<0.01$ & $1.331 .12-1.59$ & $<0.01$ & 3.94 & $2.61-5.94$ & $<0.01$ & 3.70 & $2.47-5.55$ \\
\hline [ & $<0.01$ & $1.691 .47-1.95$ & $<0.01$ & 5.96 & $4.28-8.29$ & $<0.01$ & 5.77 & $4.15-8.01$ \\
\hline & $<0.01$ & $4.864 .27-5.54$ & $<0.01$ & 41.11 & $30.44-55.50$ & $<0.01$ & 40.73 & $30.57-54.27$ \\
\hline
\end{tabular}




\begin{tabular}{|c|c|c|c|c|c|c|}
\hline \multirow[t]{2}{*}{ sification } & \multicolumn{6}{|c|}{ Cox regression analysis SD model analysis } \\
\hline & 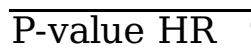 & $95 \%$ CI & P-value 1 & $\mathrm{HR} 95 \% \mathrm{CI}$ & $\overline{\mathrm{P} \text {-value } \mathrm{F}}$ & HR $95 \% \mathrm{CI}$ \\
\hline \multicolumn{7}{|l|}{ ology } \\
\hline pillary & - & - & - & - & - & - \\
\hline llicular & $<0.01 \quad 1.22$ & $1.06-1.40$ & $<0.01$ & $1.441 .15-1.79$ & $<0.01$ & $1.461 .20-1.78$ \\
\hline dullary & $<0.01 \quad 1.51$ & $1.27-1.80$ & $<0.01$ & $1.671 .33-2.14$ & $<0.01$ & $1.811 .44-2.27$ \\
\hline aplastic & $<0.016 .74$ & $5.70-7.97$ & $<0.01$ & 6.14 4.79-7.87 & $<0.01$ & $9.347 .71-11.31$ \\
\hline \multicolumn{7}{|l|}{ gery } \\
\hline is & - & - & - & - & & - \\
\hline 0 & $<0.01 \quad 1.99$ & $1.71-2.30$ & $<0.01$ & $1.711 .37-2.12$ & $<0.01$ & $2.061 .72-2.46$ \\
\hline \multicolumn{7}{|l|}{ ioiodine } \\
\hline is & - & - & - & - & - & - \\
\hline one & $<0.011 .35$ & $1.23-1.48$ & 0.02 & $1.181 .02-1.37$ & $<0.01$ & $1.251 .09-1.44$ \\
\hline \multicolumn{7}{|l|}{ motherapy } \\
\hline is & - & - & - & - & - & \\
\hline o/Unknown & $<0.01 \quad 0.61$ & $0.52-0.74$ & $<0.01$ & $0.530 .41-0.70$ & $<0.01$ & $0.730 .61-0.89$ \\
\hline \multicolumn{7}{|l|}{ e metastases } \\
\hline 0 & - & - & - & - & - & - \\
\hline is & 0.14 & $0.94-1.57$ & 0.22 & $1.190 .90-1.58$ & 0.26 & $1.170 .89-1.55$ \\
\hline nknown & 0.90 & $0.34-2.33$ & 0.87 & $0.910 .29-2.84$ & 0.97 & $0.98 \quad 0.33-2.91$ \\
\hline \multicolumn{7}{|l|}{ in metastases } \\
\hline 0 & - & & - & - & - & - \\
\hline is & $<0.01 \quad 1.93$ & $1.24-3.00$ & 0.09 & $1.720 .92-3.21$ & 0.01 & $1.771 .12-2.80$ \\
\hline nknown & $0.41 \quad 1.65$ & $0.50-5.46$ & 0.23 & $2.270 .60-8.52$ & 0.11 & $2.920 .78-10.89$ \\
\hline \multicolumn{7}{|l|}{ r metastases } \\
\hline 0 & - & & - & - & - & - \\
\hline is & $<0.01 \quad 2.23$ & $1.46-3.39$ & $<0.01$ & $2.171 .41-3.35$ & $5<0.01$ & $2.361 .52-3.66$ \\
\hline nknown & 0.78 & $0.22-3.11$ & 0.48 & $0.560 .12-2.75$ & 0.20 & $0.380 .09-1.66$ \\
\hline \multicolumn{7}{|l|}{ g metastases } \\
\hline 0 & - & & - & - & - & - \\
\hline is & $<0.01 \quad 2.31$ & $1.92-2.77$ & $<0.01$ & $2.592 .07-3.24$ & $<0.01$ & $2.42 \quad 1.97-2.98$ \\
\hline nknown & 0.99 & $0.45-2.17$ & 0.75 & $1.160 .46-2.94$ & 0.66 & $1.210 .51-2.87$ \\
\hline
\end{tabular}

Figures 

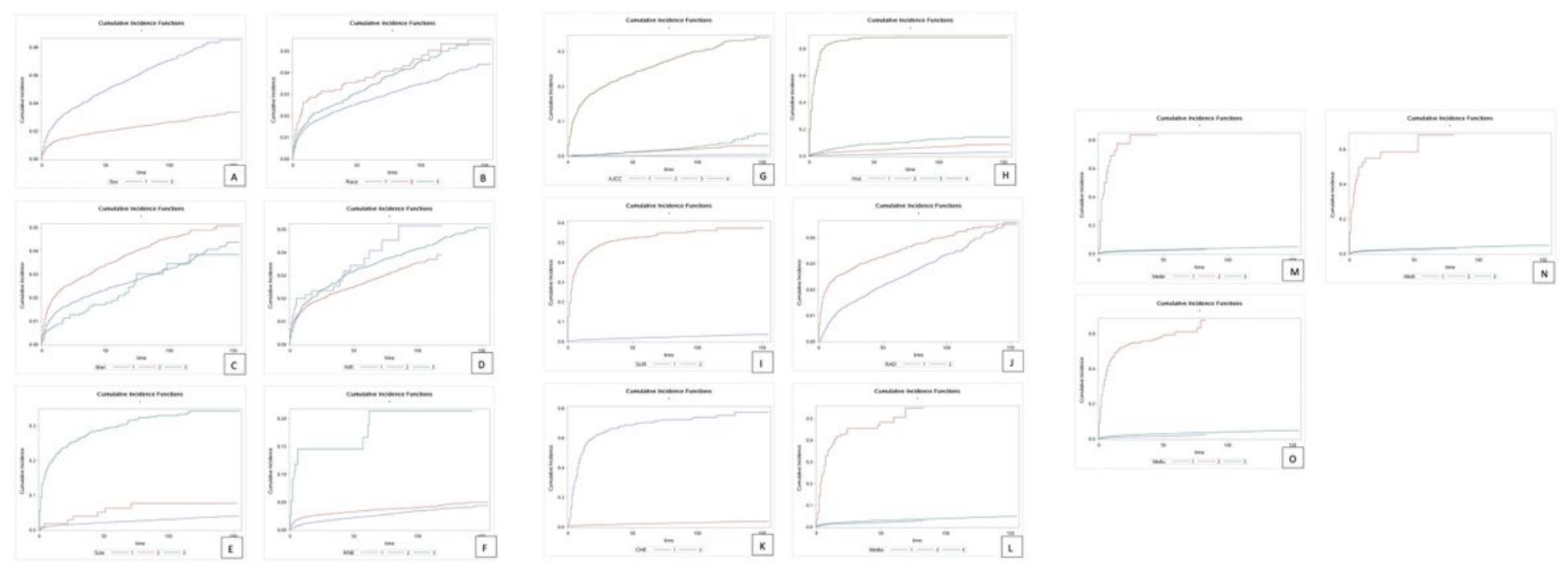

\section{Figure 1}

CIF of death due to thyroid carcinoma over time-month Abbreviations: CIF: The cumulative incidence function; Sex: 1 Male, 2 Female; Race: 1 White, 2 Black, 3 Other; Mari(Married State): 1 Married, 2 Unmarried, 3 Unknown; INR(Insurance Recode): 1 Uninsured, 2 Insured and Any Medicaid, 3 Unknown; Size: $1 \leq 1 \mathrm{~cm}, 2>1 \mathrm{~cm}$, 3Unknown; RNE(Regional nodes Examined): 1 Yes, 2 None, 3 Unknown; AJCC-6: 1 I, 2 II, 3 III, 4 IV; Hist (histology): 1 Papillar, 2 Follicular, 3 Medullary, 4 anaplastic; SUR(Surgery) 1 Yes, 2 No; RAD(Radioiodine): 1 Yes, 2 None; CHE(Chemotherapy): 1Yes, 2 No/Unknow; Metbo(Bone metastases): 1 No, 2 Yes, 3 Unknown; Metbr(Brain metastases): 1 No, 2 Yes, 3 Unknown; Metli(Liver metastases): 1 No, 2 Yes, 3 Unknown; Metlu(Lung metastases): 1 No, 2 Yes, 3 Unknown; 